\title{
Perencanaan E-Commerce Sebagai Strategi Penjualan Produk Batik Tenun Di Kota Kediri
}

\author{
Nizar Zakaria ${ }^{1}$, Fauziyah Annisa ${ }^{2}$ \\ ${ }^{1,2}$ Teknik Informatika Universitas Wahidiyah Kediri \\ E-mail: 1)zakaria_neezar@yahoo.co.id, ${ }^{2)}$ fauziyahrahma@0015.gmail.com
}

\begin{abstract}
Abstrak - Dalam dunia bisnis, website dalam bentuk e-commerce sudah merupakan kebutuhan dari suatu bisnis untuk mengembangkan usaha karena memiliki berbagai manfaat. Ecommerce memiliki manfaat yang sangat besar bagi pelaku usaha, antara lain para konsumen tidak perlu datang ke toko penjual untuk memilih barang yang ingin dibeli, dan dari segi keuangan konsumen dapat menghemat biaya yang dikeluarkan, apabila lokasi toko jauh, konsumen dapat menghemat ongkos perjalanan dengan diganti biaya pengiriman yang jauh lebih murah dan bermanfaat bagi pengguna, maka dapat dilihat bahwa penerapan teknologi informasi yang baru itu dapat diterima oleh pengguna.Tujuan penelitian ini adalah mendiskripsikan sistem penjualan yang berjalan saat ini, mengidentifikasi permasalahan yang ada serta melakukan Implementasi ECommerce guna memberikan solusi atas permasalahan yang dihadapi. Teknik pengumpulan data dalam penelitian ini adalah melalui proses wawancara dengan narasumber, observasi langsung beberapa proses yang ada, dan studi pustaka mengenai Implementasi E-Commerce. Hasil penelitian ini adalah melakukan Implementasi Sistem E-Commerce dengan menggunkan program open source bernama Prestashop. Dengan menggunakan Prestashop sistem penjualan dapat berjalan dengan baik dimana para pelaku usaha batik tenun tidak perlu menggunakan media promosi berupa penyebaran brosur serta spanduk yang membutuhkan biaya yang banyak. Dengan melakukan Implementasi E-Commerce menggunakan program prestashop sistem akan berjalan dengan lebih efektif dan efisien.
\end{abstract}

Kata Kunci-E-Commerce, Open Source, Prestashop.

Abstract - In the business world, a website in the form of e-commerce is a necessity of a business to develop a business because it has various benefits. E-commerce has huge benefits for businesses, among others consumers do not need to come to the seller's shop to choose the items they want to buy, and in terms of financial consumers can save costs incurred, if the store location is far away, consumers can save on travel costs by replacing shipping costs that are much cheaper and useful for users, it can be seen that the application of new information technology can be accepted by users. The purpose of this study is to describe the current sales system, identify existing problems and implement e-commerce in order to provide solutions to the problems encountered. Data collection techniques in this research is through the process of interviews with sources, direct observation of several existing processes, and literature studies on the Implementation of ECommerce. The results of this study are implementing the E-Commerce System by using an open source program called Prestashop. By using Prestashop the sales system can run well where the batik weaving businesses do not need to use promotional media in the form of distributing brochures and banners that require a lot of money. By implementing E-Commerce using the prestashop program the system will run more effectively and efficiently.

Keywords - E-Commerce, Open Source, Prestashop .

\section{PENDAHULUAN}

Perkembangan teknologi informasi yang sangat pesat dari waktu kewaktu sudah terasa manfaatnya oleh sebagian besar orang baik dalam bidang pendidikan, kesehatan, hiburan, sumber informasi, dunia bisnis dan komunikasi tanpa batasan tempat dan waktu. Internet merupakan salah satuteknologi informasi komunikasi terkini, internet memiliki jangkauan yang hampir tak terbatas dan menjangkau hamper semua kalangan di masyarakat Indonesia. Menurut McLeod (2008 : 59), ecommerce adalah penggunaan jaringan komunikasi dan computer untuk melakukan proses bisnis. Pandangan masyarakat terhadap e-commerce adalalah penggunaan internet dan computer dengan browser web untuk membeli dan menjual produk. Dalam dunia bisnis, website dalam bentuk e- 
commerce sudah merupakan kebutuhan dari suatu bisnis untuk mengembangkan usaha karena memiliki berbagai manfaat.

E-commerce memiliki manfaat yang sangat besar bagi pelaku usaha, antara lain para konsumen tidak perlu datang ke toko penjual untuk memilih barang yang ingin dibeli, dan dari segi keuangan konsumen dapat menghemat biaya yang dikeluarkan, apabila lokasi toko jauh, konsumen dapat menghemat ongkos perjalanan dengan diganti biaya pengiriman yang jauh lebih murah dan bermanfaat bagi pengguna, maka dapat dilihat bahwa penerapan teknologi informasi yang baru itu dapat diterima oleh pengguna. Kebanyakan para pelaku bisnis yang usahanya masih belum memiliki omset tinggi lebih memilih menggunakan sistem penjualan secara konvensional.

Para pelaku bisnis memperhitungkan bahwa biaya dalam pembuatan website yang terlalu tinggi tidak seimbang dengan jumlah pendapatan yang diterima. Sebagai contoh pada para pelaku UMKM batik tenun di Desa Bandar Kota Kediri yang menjual berbagai jenis kain batik tenun. Desa Bandar merupakan sentra batik tenun di Kota Kediri, dimana beberapa warganya menggeluti usaha sebagai pengrajin batik tenun. Sampai pada saat ini proses penjual produk UMKM tersebut masih dilakukan secara konvensional, dengan menjual di toko setiap masing-masing rumah pelaku usaha tersebut. Proses penjulan secara konvensional ini dirasa kurang maksimal, karena pembeli berhubungan langsung dengan mendatangi toko batik tenun di Desa Bandar Kota Kediri. Dengan demikian, pembeli membutuhkan biaya lebih banyak dan waktu yang cukup lama untuk membeli kain batik tenun yang diinginkan.

Platform prestashop merupakan aplikasi gratis berbasis open source yang digunakan sebagai media pembuat toko online atau website e-commerce, danaplikasi lainnya yang tergolong gratis seperti joomla, magento, opencart danlain-lain. Alasan peneliti menggunakan prestashop sebagai pembuat website e-commerce dikarenakan prestashop memiliki banyak keunggulan seperti tampilan user interface yang menarik serta banyak modul-modul gratis yangdapat menunjang pengoperasian website e-commerce.

\section{a. E-Commerce}

\section{METODE PENELITIAN}

E-commerce merupakan suatu tindakan melakukan transaksi bisnis secara elektronik dengan menggunakan internet sebagai media komunikasi yang paling utama. Dalam memanfaatkan suatu sistem tidak dapat dilakukan tanpa ada perencanaan. Perencanaan sistem wajib dilakukan agar mendapatkan kesesuain antara kebutuhan sistem dengan kondisi bisnis.

Perencanaan strategis sistem informasi yang dirancang untuk semua proses bisnis, juga harus mempunyi peran yang signifikan dalam memenuhi parameter-parameter tersebut. Dalam proses bisnis produksi, implementasi Teknologi Infornasi dan Sistem Informasi yang efisien dipakai untuk menyampaikan semua informasi yang berkaitan dengan pelayanan prima terhadap konsumen secara cepat dan tepat, dan informasi yang jasa pelayanan bisa sesuai dengan apa yang diinginkan.

Penggunaan e-commerce sangat memudahkan konsumen untuk melakukan transaksi pembelian produk batik, semua data konsumen dapat kita kelola guna strategi pemasaran produk yang lainnya.

\section{b. Analisis SWOT}

Perencanaan strategis dalam membuat sistem harus disertai dengan metode yang dapat mendeskripsikan kebutuhan sistem. Salah satu dengan menggunakan analisis SWOT. Analisis SWOT merupakan instrumen perencanaan strategis dengan menggunakan kerangka kerja kekuatan dan kelemahan dan kesempatan eksternal dan ancaman, instrumen ini memberikan cara sederhana untuk memperkirakan cara terbaik untuk melaksanakan sebuah strategi. Instrumen ini menolong para perencana apa yang bisa dicapai, dan hal-hal apa saja yang perlu diperhatikan oleh mereka.

Analisis SWOT memiliki instrumen yang beraneka guna, yang dapat digunakan berkalikali pada berbagai tahap proyek; membangun sebuah telaah atau untuk pemanasan diskusi sebelum membuat perencanaan. Instrumen ini dapat diterapkan secara luas, atau sub-komponen yang kecil (bagian dari strategi) dapat dipisahkan agar dapat melakukan analisis yang mendetail. Komponen analisis SWOT antara lain sebagai berikut:

- Strength (Kekuatan)

- Weakness (Kelemahan)

- Opportunity (Peluang)

- Threat (Ancaman) 


\section{c. Analisis PIECES}

Selain analisis SWOT dalam merencanakan sistem proses bisnis, analisis PIECES tidak kalah pentingnya. Masing-masing mempunyai peran dalam strategi proses bisnis.
Dengan
menggunakan
metode
PIECES

Performance,Information,Economy,Control,Efficiency dan Security ). Penulis mengindentifikasi masalah - masalah ataupun kelemahan-kelemahan yang terdapat pada sistem yang di terapkan pada e-commerce nantinya dalam perkembangannya. Untuk membantu mengidentifikasikan , menganalisis dan memecahkan masalah, maka digunakanlah kerangka PIECES, berikut ini diuraikan rincian permasalahan yang muncul pada sistem. Analisa PIECES meliputi :

1. Performance (kinerja)

2. Information (Informasi)

2. Economy (Ekonomi)

4. Controlling (Pengendalian)

5. Eficiency

6. Service (pelayanan)

Tentunya implementasi strategi sistem infotmasi dalam pemasaran produk yang baik harus didukung dengan dasar kerangka yang bagus, oleh karena itu dibutuhkan Sumber Daya Manusia yang dapat memahami serta mengoperasikan sistem e-commerce.

\section{HASIL DAN PEMBAHASAN}

3.1. E-commerce memiliki beberapa komponen dalam transaksi bisnis yang dilakukan secara offline, yaitu (Hidayat, 2008:7):

1. Produk (Product): Banyak jenis produk yang bias dijual melalui internet.

2. Tempat (a place to sell): tempat menjual adalah internet yang berarti harus memiliki domain dan hosting.

3. Penerima pesan (Receive): email, telpon, sms dan lain-lain.

4. Pembayaran (Payment): Cash, cek, bank draft, kartu kredit, internet payment (misalnya paypal).

5. Pengiriman (Shipping): pengiriman bisa dilakukan melalui paket,salesman, atau di download jika produk yang dijual memungkinkan untuk itu (misalnya software).

6. Pelayanan (Customer service): email, formulir online, FAQ, telpon, chatting, danlain-lain.

\section{a. Penggolongan E-Commerce}

Penggolongan e-commerce yang lazim dilakukan masyarakat adalah berdasarkan sifat transaksinya Suyanto (2003:4) menjelaskan tipe-tipe transaksi dalam e-commerce, sebagai berikut:

1. Bussiness to business (B2B)

2. Bussiness to Consumer (B2C)

3. Consumer to Consumer (C2C)

4. Consumer to Bussiness (C2B)

\section{b. Metode Pembayaran di E-Commerce}

Terdapat 3 metode pembayaran yang sering dilakukan dalam transaksi menggunakan e-commerce (Prihatna, 2005:19):

1. Online Processing Credit Card 
Metode ini cocok digunakan untuk produk yang bersifat retail dimana pasarnya adalah seluruh dunia. Pembayaran dilakukan secara real time (proses verifikasi saat itu juga).

\section{Money Transfer}

Cara ini lebih aman untuk menerima pembayaran dari konsumen mancanegara, namun memerlukan biaya tambahan bagi konsumen dalam bentuk fee bagi pihak penyedia jasa money transfer untuk mengirim sejumlah uang ke negara lain.

\section{Cash on Delivery}

Pembayaran dengan bayar di tempat ini hanya bisa dilakukan jika konsumen berada dalam satu kota yang sama dengan penyedia jasa.

\section{c. Siklus Pengembangan Sistem Informasi}

Saat ini kebutuhan akan informasi sangat vital, karena informasi memegang peranan penting dalam kegiatan organisasi. Informasi ibarat darah yang mengalir dalamtubuh suatu organisasi, karena itu organisasi kekuranganinformasi akan lemah dan akhirnya hancur.

Data merupakan bagian atau eleven dari suatu informasi. Data belum mampu memberikan tambahan ilmu pengetahuan atau temuan tertentu, data ádalah kenyataan yang menggambarkan sutau kejadian (event). Data merupakan bahan mentah dari informasi, sebagai bahan mentah data tidak mempunyai kegunaan atau arti bagi para pemakainya. Oleh karena itu data perlu di olah lebih lanjut untuk menghasilakn informasi.

Data dapat disimpan dahulu atau langsung menjadi informasi. Jadi data masukan dapat berasal dari sistem (database) atau dapat pula dari luar sistem. Informasi ádalah data yang telah diolah menjadi bentuk yang telah berguna dan lebih berarti bagi penerimanya [4]. Penerima (pemakai) menerima informasi tersebut, kemudian membuat suatu keputusan dan melakukan tindakan. Tindakan itu menghasilakan sejumlah data (data baru) mengenai hasil kegiatan. Data tersebut akan ditangkap sebagai input dilewat kembali melalui proses dan seterusnya membentuk statu siklus yang disebut siklus Informasi. Dalam pembuatan sebuah sistem informasi juga memperhatikan tentang siklus pengembangan sistem informasi [5]. Berikut gambar siklus pengembangan sistem:

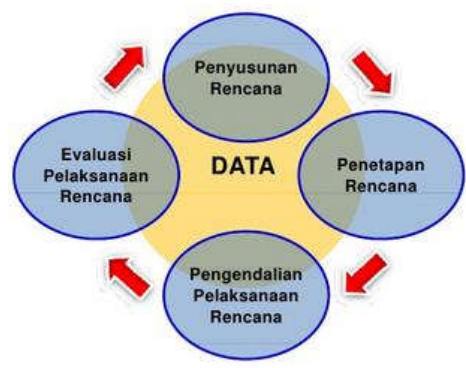

Gambar 1. Siklus pengembangan sistem (Sumber Jogiyanto HM, 2005) 
Dari gambar diatas dapat dideskripsikan bahwasannya sumber dari proses bisnis ini adalah data. Mulai dari penyusunan perencanaan hingga evaluasi harus dilakukan secara detail. Agar setiap tahapan dapat dilakukan secara baik, perlu adanya analisa objek, adapun metode analisa data, yaitu dengan menggunakan analisis SWOT. Analisis SWOT memiliki instrumen yang beraneka guna, yang dapat digunakan berkali-kali pada berbagai tahap proyek; membangun sebuah telaah atau untuk pemanasan diskusi sebelum membuat perencanaan. Instrumen ini dapat diterapkan secara luas, atau sub-komponen yang kecil (bagian dari strategi) dapat dipisahkan agar dapat melakukan analisis yang mendetail.

Strength (Kekuatan); situasi atau kondisi yang merupakan kekuatan dari organisasi atau program pada saat ini.

Weakness (Kelemahan); situasi atau kondisi yang merupakan kelemahan dari organisasi atau program pada saat ini.

Opportunity (Peluang); situasi atau kondisi yang merupakan peluang diluar organisasi dan memberikan peluang berkembang bagi organisasi dimasa depan.

Threat (Ancaman); situasi yang merupakan ancaman bagi organisasi yang datang dari luar organisasi dan dapat mengancam eksistensi organisasi dimasa depan.

\begin{tabular}{|c|c|}
\hline Strength & Weakness \\
\hline $\begin{array}{ll}\text { 1. } & \text { Usaha dikelola } \\
\text { pribadi } \\
\text { 2. } & \text { Lokasi strategis } \\
\text { 3. } & \text { Kemudahan } \\
\text { pelayanan } \\
\text { 4. }\end{array}$ & $\begin{array}{l}\text { 1. Satu sistem untuk } \\
\text { semua pelaku } \\
\text { usaha umkm. } \\
\text { 2. } \begin{array}{l}\text { Pengenalan } \\
\text { sistem kepada } \\
\text { masyarakat }\end{array} \\
\text { 3. } \\
\text { Biaya Tinggi }\end{array}$ \\
\hline Opportunities & Trearts \\
\hline 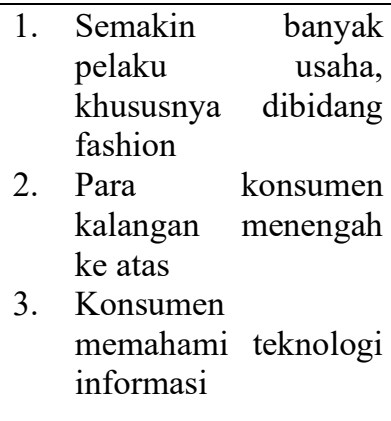 & $\begin{array}{l}\text { 1. } \begin{array}{l}\text { Banyak sistem e- } \\
\text { commerce yang } \\
\text { menjual produk } \\
\text { fashion maupun } \\
\text { batik }\end{array} \\
\text { 2. Persaingan harga } \\
\text { 3. Sumber daya } \\
\text { Manusia }\end{array}$ \\
\hline
\end{tabular}

\section{d. Analisis PIECES}

Selain analisis SWOT dalam merencanakan sistem proses bisnis, analisis PIECES tidak kalah pentingnya. Masing-masing mempunyai peran dalam strategi proses bisnis.

Dengan menggunakan metode PIECES ( Performance, Information, Economy, Control, Efficiency dan Security ). Penulis mengindentifikasi masalah - masalah ataupun kelemahankelemahan yang terdapat pada sistem yang di terapkan pada e-commerce nantinya dalam perkembangannya. Untuk membantu mengidentifikasikan, menganalisis dan memecahkan masalah, 
maka digunakanlah kerangka PIECES, berikut ini diuraikan rincian permasalahan yang muncul pada sistem. Analisa PIECES meliputi :

1. Performance (kinerja)

Performance adalah kemampuan dalam menyelesaikan tugas dengan cepat sehingga sasaran dapat segera tercapai. Pada sistem e-laundry proses pengolahan data tersistem dan pelayanan konsumen menggunakan perangkat aplikasi mobile. Terkendala dalam segi penguna layanan aplikasi yang tidak bisa terkontrol. Operator harus memastikan sistem bisa berjalan sesuai ketentuan dan kurir bisa tepat di lokasi konsumen.

\section{Information (Informasi)}

Dengan bisnis dengan sistem baru ini , promosi tentang keunggulan sistem online perlu di gencarkan untuk masyarakat lebih cepat dan mudah dalam penggunaannya nanti. Mempromosikan sistem yang belum banyak orang mengetahuinya, maka pemilik usaha batik tenun ikat membutuhkan mekanisme promosi yang bisa langsung mengena kepada pelanggan.

\section{Economy (Ekonomi)}

Dari segi Sistem e-commerce membutuhkan dana investasi lebih untuk membangun infrastruktur, membangun Teknologi Informasi, maupun Sistem Informasinya. Dai segi konsumen, mayoritas masyarakat menggunakan smartphone.

\section{Controlling (Pengendalian)}

Kontrol dalam sebuah sistem sangat diperlukan keberadaannya untuk menghindari dan mendeteksi penyalahgunaan atau kesalahan sistem serta untuk menjamin keamanan data dan informasi. Data yang tersedia saat ini masih terpisah - pisah. Untuk Mengelola data para pelaku usaha batik tenun ikat di daerah tersebut harus terdapat operator atau administrator yang bisa memastikan apakah sistem sudah berjalan sesuai dengan kebutuhan yang diharapkan.

\section{Eficiency}

Cara ini memberikan solusi untuk mendukung terciptanya kegiatan usaha yang diharapkan di dalam sistem baru ini, karena dalam kegiatan pencatatan data administrasi harus dilakukan penyalinan secara efisien dalam data konsumen. Dan Pengguna harus mempelajari sistem yang untuk melakukan transaksi menggunakan e-commerce.

\section{Service (pelayanan)}

Dari hasil analisa SWOT dan PIECES terlihat bahwa banyak aplikasi yang harus dikembangkan untuk menutup kelemahan yang dimiliki di setiap bentuk usaha jasa laundry sehingga implementasi dari aplikasi harus dilakukan dapat dimaksimalkan.

Tidak hanya dari sisi strategi dan teknologi, diharapkan juga pengembangan manajemen SDM. Untuk mengimplimentasikan aplikasi tersebut. Saran yang diberikan untuk Pengembang bisnis batik tenun untuk dapat mengimplementasikan strategi Teknologi Informasi maupun Sistem Informasi, adalah sebagai berikut:

Mempercepat proses penguatan peran bisnis unit Teknologi Informasi.

Melakukan promosi melalui e-commerce.

Tentunya implementasi strategi sistem infotmasi dalam pemasaran produk yang baik harus didukung dengan dasar kerangka yang bagus, oleh karena itu dibutuhkan Sumber Daya Manusia yang dapat memahami serta mengoperasikan sistem e-commerce.

\section{e. Diagram Konteks}

Sebuah perencanaan sistem perlu adanya gambaran alur sistem agar mudah dimengerti oleh seorang pengguna. Gambaran alur sistem bisa disajikan dengan menggunakan gambar yang biasa disebut data flow diagram. 
Pada diagram konteks ini dianalisis terlebih dahulu sistem informasi yang dibuat akan menghasilkan apa saja. Setelah dihasilkan analisis diagram konteks, kemudian dilanjutkan dengan analisis Data Flow Diagram.

Data Flow Diagram adalah teknik grafis yang menggambarkan aliran informasi dan perubahan yang digunakan sebagai perpindahan data dari masukan ke keluaran. Berikut DFD dari sistem ini:

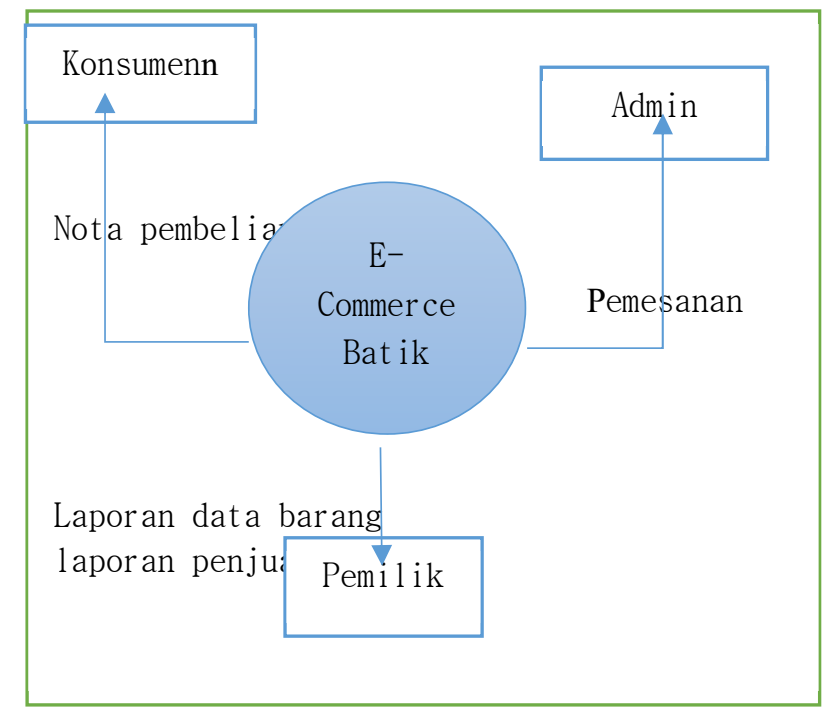

Gambar 2. Diagram Konteks

Dari gambar diatas dapat dideskripsikan bahwa sistem yang dibuat menyesuaikan kebutuhan proses bisnis. Setiap agent mempunyai peran sendiri-sendiri. Alur proses pembelian produk tenun secara konvensional yaitu ketika konsumen atau pembeli datang ke toko untuk memilih dan membeli tenun, maka pembeli mendapatkan nota pembelian dari kasir. Setelah itu untuk laporan jumlah barang keluar, kasir memberikan laporan ke pemilik toko. Hal itu berlaku sama untuk e-commerce, yaitu ketika pembeli memilih barang dan melakukan pembelian akan muncul total yang harus dibayarkan dan dilakukan secara transfer. Dari sistem ini pemilik toko, melalui admin bisa melihat laporan barang.

\section{f. Implementasi}

Aplikasi yang dibuat ini akan digunakan oleh admin terdahulu dengan membuat account atau hak akses sistem, kemudian calon pendaftar mengakses halaman yang telah ditentukan oleh admin. Prestashop tools yang digunakan penulis untuk memenuhi kebutuhan proses bisnis.

\section{SIMPULAN}

Penelitian ini mempunyai kesimpulan sebagai berikut:

1. Pemanfaatan e-commerce guna menunjang dalam proses pemasaran produk batik tenun ikat dengan menggunakan platform Content Management System Prestashop.

2. Pengembangan manajamen SDM untuk mengimplemtasikan sistem informasi yang diperlukan.

\section{DAFTAR PUSTAKA}

[1] McLeod, R. dan Schell, Jr., G. P., 2008, Management Information System, Edisi 10,Jakarta: Salemba Empat.

[2] Hidayat, Taufik. 2008. Panduan Membuat Toko Online dengan OSCommerce, Jakarta :Mediakita 
[3] Prihatna, Henky. 2005. Kiat praktis menjadi web master professional. Jakarta. : PT.Elexmedia computer.

[4] Fatta, Hanif Al.2007 “Analisis \& Perancangan Sistem informasi”,.Yogyakarta Penerbit ANDI.

[5] Jogiyanto, H.M., (2005), Analisa dan Desain Sistem Informasi: Pendekatan Terstruktur Teori dan Praktik Aplikasi Bisnis, ANDI, Yogyakarta

[6] Jogiyanto, HM. 2009. Analisis dan Desain. Yogyakarta : Andi OFFSET

[7] Jogiyanto, 2010. Analisis dan Desain Sistem Informasi, Edisi IV, Andi Offset, Yogyakart. 